Article

\title{
Experimental Investigation on the Creep Property of Carbon Fiber Reinforced Polymer Tendons under High Stress Levels
}

\author{
Dong Yang ${ }^{1}$, Jiwen Zhang ${ }^{1,2, *}$, Shoutan Song ${ }^{1,2}$, Fei Zhou ${ }^{1}$ and Chao Wang ${ }^{1}$ \\ 1 School of Civil Engineering, Southeast University, Nanjing 210096, China; dongyang@seu.edu.cn (D.Y.); \\ songshoutan@seu.edu.cn (S.S.); zhoufei0912@seu.edu.cn (F.Z.); chao.wang.seu@gmail.com (C.W.) \\ 2 Key Laboratory of Concrete and Prestressed Concrete Structures of the Ministry of Education, \\ Southeast University, Nanjing 210096, China \\ * Correspondence: jw.zhang.seu@outlook.com; Tel.: +86-139-5101-2494
}

Received: 21 October 2018; Accepted: 9 November 2018; Published: 14 November 2018

\begin{abstract}
Carbon fiber reinforced polymer (CFRP) tendons are generally used as prestressing members to take full advantage of their high strength. Their creep property is one of the key factors influencing the reliability and safety of the structures, especially under sustained high stress. In this study, using a new wedge-type anchorage system, experimental research was carried out on the creep behavior of CFRP tendons under high stress levels from 0.69 to $0.85 f_{u}$. All the tests lasted for a duration of $1000 \mathrm{~h}$. It was found that the creep coefficient tends to increase with the stress level. Compared to their static properties, the residual strength of CFRP tendons after creep tests is $4.54 \%$ lower while the after-creep elastic modulus is $6.99 \%$ higher. Through data analysis, a semi-logarithm linear relationship between the creep coefficient and time was established, and the creep coefficients at 1 million hours were extrapolated.
\end{abstract}

Keywords: carbon fiber reinforced polymer (CFRP); long-term property; creep

\section{Introduction}

Fiber reinforced polymer (FRP) materials are characterized by many excellent properties, such as low weight, high strength, corrosion resistance, and non-magnetism. They have shown promising application potential for building retrofitted and concrete structures under a corrosive environment [1-3]. At present, the most commonly used FRP materials are aramid FRP (AFRP), glass FRP (GFRP), basalt FRP (BFRP), and carbon FRP (CFRP). Among all the FRP materials, CFRP exhibits the best performance and is the most ideal substitute material for steel.

Owing to their high strength and relatively low elastic modulus, CFRP tendons are a common preference in civil engineering for use as prestressing members to take full advantage of their high performance [4]. However, the creep property of CFRP materials may lead to the stress redistribution of different structural components, subsequently influencing the reliability and durability of the structures $[5,6]$. For civil engineering structures, including bridges, the designed service life is generally over 50 years. The lack of understanding of the creep property of CFRP materials has partly limited the application of these materials.

Besides this, due to the low transverse strength and delicate surface of CFRP tendons, a feasible and reliable anchorage system for the CFRP tendons under sustained load is also one of the key problems to be solved. A new wedge-type anchorage system was developed by the authors' research group and was used in this study for a series of tests on the creep behavior of CFRP tendons. The long-term performance of the anchorage system was also investigated. 


\section{Literature Review}

Creep is the outward manifestation of FRP materials' viscoelastic property. It is induced by three circumstances: (a) the straightening of uneven fibers, (b) the viscoelastic deformation of the resin matrix, and (c) the creep of fibers [7]. A lot of studies have already been carried out on CFRP tendons [8,9]. However, only limited references are available on the long-term behavior of CFRP tendons in the current literature. The previous research on the creep behavior of CFRP tendons can be divided into two categories: research on the creep rupture properties and research on the creep strain under different stress levels. Yamaguchi [10] studied the creep rupture phenomenon of CFRP rods and revealed a semi-logarithm relationship between the creep rupture stress and time. Through extrapolation, he determined the creep rupture strength of CFRP rods after 1 million hours to be $0.92 \mathrm{fu}$. Ando [11] found the creep rupture behavior of twisted CFRP bars to be independent of the sectional dimension and calculated the creep rupture strength to be $0.79 \mathrm{fu}$ after 50 years. Hamid Saadatmanesh [12] tested the creep performance of both CFRP tendons (Leadline) and twisted CFRP cables (CFCC) subjected to stress levels of $0.4 \mathrm{fu}$. No creep was observed for Leadline, and the creep strain of the CFCCs at $3000 \mathrm{~h}$ was $0.015 \%$. Patrick X. W. Zou [13] also reported the creep coefficient of CFRP tendons (Leadline) to be zero for stress levels below $0.6 f_{u}$. Xiong Yang [14] conducted a series of creep tests on CFRP cables at $95 \%$ of their guaranteed capacity for 5 months. Neither rupture nor any sign of distress was observed. The residual strength of the specimens was $14 \%$ lower than the static strength but still higher than the guaranteed capacity.

It can be concluded from the literature cited above that CFRP tendons possess a high creep rupture strength and low creep coefficient. However, a relatively large discrepancy exists in the creep property of CFRP tendons provided by different manufactories. Even when using identical tendons, the conclusions drawn by different researchers are not exactly consistent. In addition, little data on the creep coefficient of CFRP tendons are available, especially for high stress levels over $0.60 f_{u}$.

On the other hand, there is also continuing concern regarding efficient and reliable anchorages for CFRP tendons. There are two main types of anchorages for CFRP tendons at present: the bonded anchorage and mechanical anchorage. Bonded anchorages come with the disadvantages of long curing times, high slippage, and long lengths. In contrast, the mechanical anchorages are preferred for structural applications because they are easy to mount [15]. Several mechanical anchorages have been developed for CFRP tendons, such as the split-wedge anchorage, nonmetallic wedge anchorage, and integrated sleeve-wedge anchorage [16]. In 2002, split-wedge anchorages were applied to the Laroin CFRP Footbridge for anchoring CFRP cables [17]. However, as a compressive force perpendicular to the tendon exists in mechanical anchorages, premature failure or local crushing at the anchorage zone is likely to take place [15]. Mechanical anchorages possessing reliability and stability still remain to be developed.

Based on the new wedge-type anchorage system developed by the authors' research group, in this study, a series of creep tests were carried out under stress levels higher than $0.60 f_{u}$ with a duration of $1000 \mathrm{~h}$. The creep coefficient, residual strength, and elastic modulus after creep were measured. The creep coefficients of CFRP tendons at 50 years and 1 million hours were predicted from $1000 \mathrm{~h}$ of test data.

\section{Materials and Methods}

\subsection{Specimen Preparation and Anchoring System}

All the tests were performed at the Testing Laboratory of Civil Engineering in Southeast University. The CFRP tendons used in this study are commercially available and were provided by Jiangsu Hengshen Co. Ltd. (Zhenjiang, China). These tendons, with a nominal diameter of $8 \mathrm{~mm}$ and a smooth surface, were manufactured by pultrusion technology using carbon fibers and epoxy resin. The fiber volume fraction of the CFRP tendons was approximately $65 \%$. 
Figure 1 presents the new wedge-type anchorage system, which was dedicated to the CFRP tendons used in the tests. The anchorage consists of a wedge, a barrel, and a nut; the soft sleeve used in common wedge-type anchorages is omitted $[15,18,19]$. Specifically, a wedge with four notches is integrated and its inner face is smooth. It is able to grip the tendon directly without injuring the material surface. Static and fatigue tests were conducted in previous research, and this type of anchorage showed a reliable performance [20].
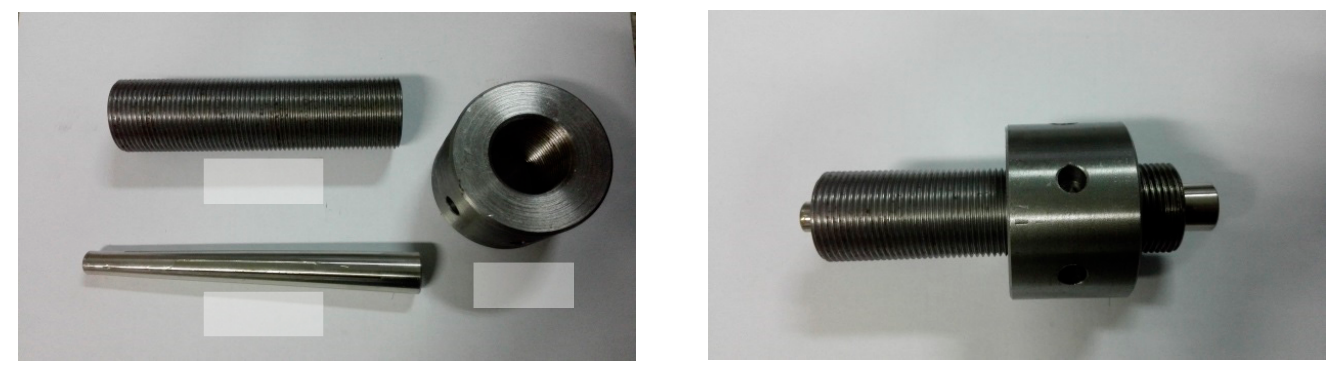

Figure 1. Wedge-type anchorage for the tests.

\subsection{Testing Setups}

\subsubsection{Static Test Setup}

The static tensile strength test setup consists of a hollow jack, a load cell, bearing plates, and loading pads, as shown in Figure 2. Three strain gauges were attached to the middle of each tendon to measure its strain. The original load and strain data were captured by a data acquisition instrument. All the specimens were loaded to failure, and the data of five specimens which did not fail at the anchorage zone were picked out to determine the static tensile strength.
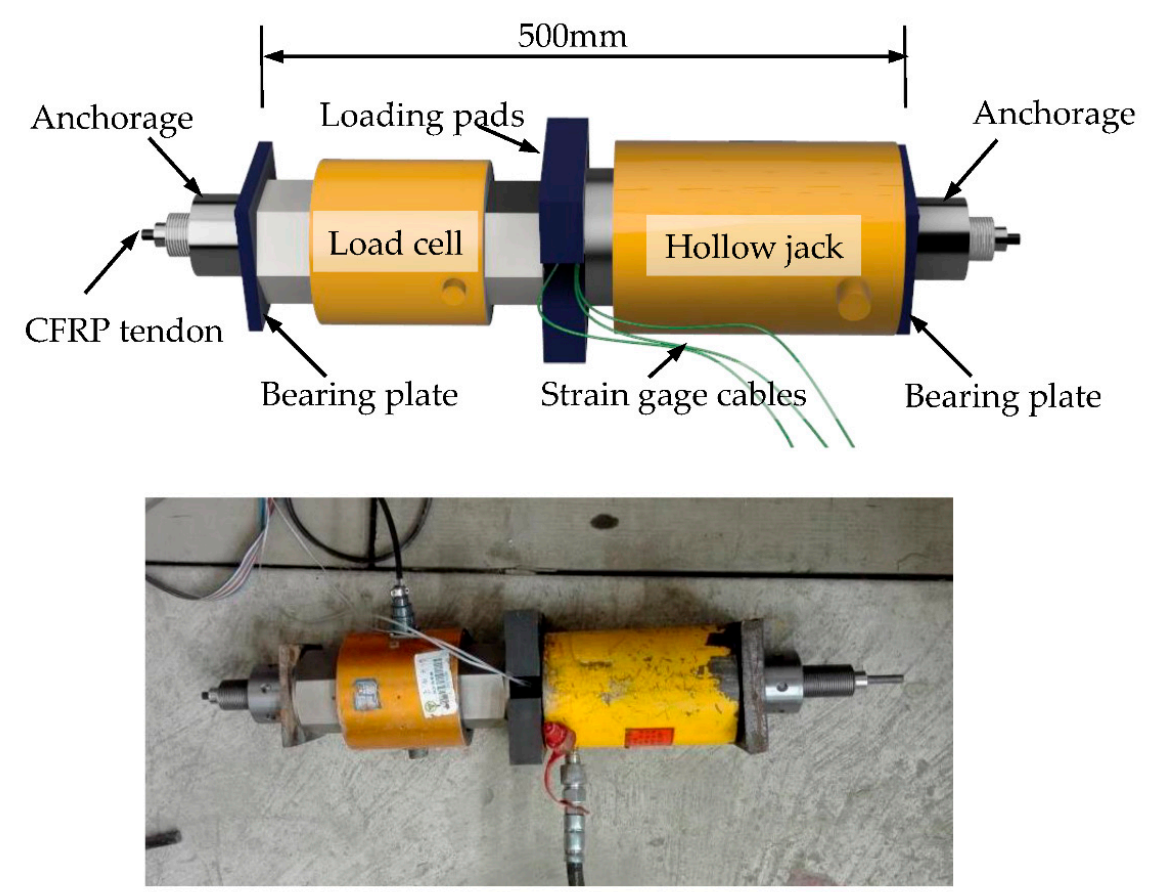

Figure 2. Static test setup.

\subsubsection{Creep Test Setup}

To maintain the load stability during the creep test on CFRP tendons, a test frame was designed and fabricated for this study (Figure 3). The frame was able to magnify the applied load by a factor of 56 through the application of the lever principle. A screw was installed at the end of the lower arm 
to adjust the alignment of two horizontal arms. The precise load applied to the CFRP tendon was measured by a load cell that was set at the anchorage zone.
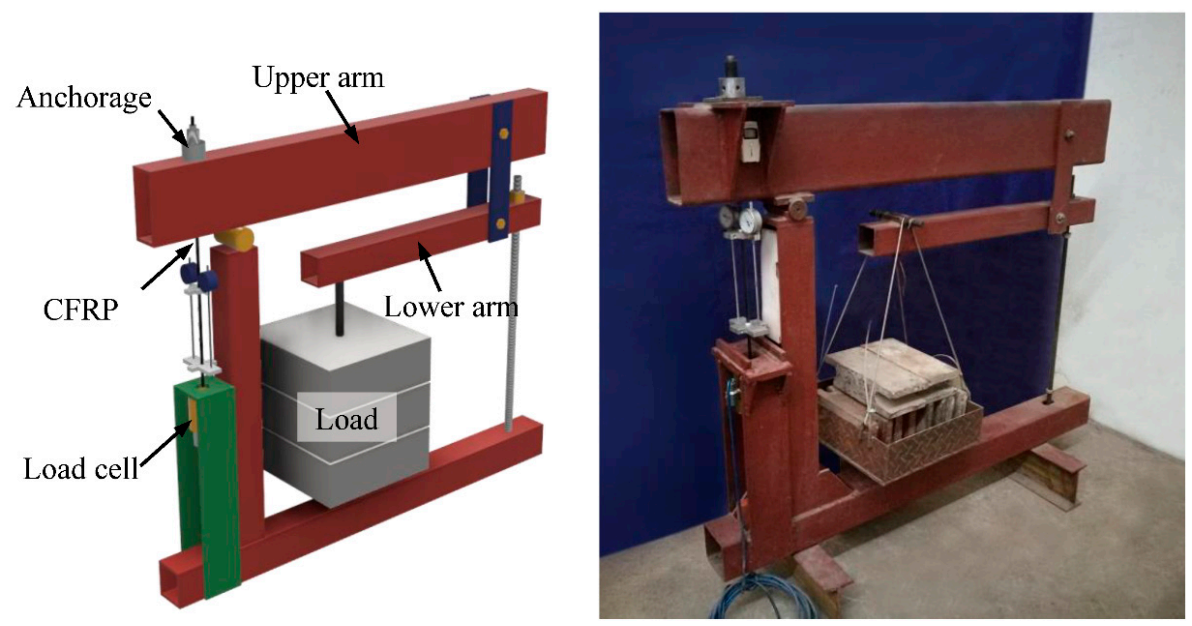

Figure 3. Creep test frame.

To measure the strain of the specimen over a long observation period, a dedicated device was used as shown in Figure 4. This device contains an upper holder, a lower holder, and two dial gauges. Both the upper holder and lower holder were divided into two symmetric parts which were connected and fixed to the tendon by bolts. As the CFRP tendon has a low transverse strength, two aluminum rings were installed between holder parts to wrap the tendon to prevent the specimen from being damaged by the extrusion force. The distance between the upper holder and lower holder was $220 \mathrm{~mm}$ and the dial gauges had a precision of $0.001 \mathrm{~mm}$. So, the precision of this measurement device was calculated to be $\mathrm{A}=0.001 / 220=44.5 \times 10^{-6}=4.5 \mu \varepsilon$. To verify the reliability of this device, three strain gauges were attached to the middle of the first specimen. The data obtained from both the device and the strain gauges were recorded during the loading process. The comparison showed that the deviation between these two data sets was less than $5 \%$, demonstrating the efficiency of this strain measurement device.

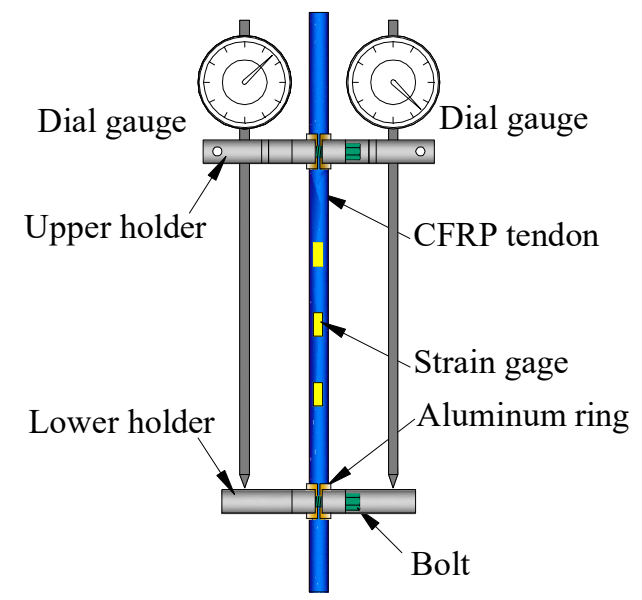

Figure 4. Strain measurement device.

\subsection{Loading Procedure}

\subsubsection{Static Test Loading Procedure}

For static tensile strength tests, the loading rate was set to be $200 \mathrm{MPa} / \mathrm{min}$. Both the load and strain data were recorded by the data acquisition instrument every second until the failure of the 
specimen. Five effective specimens without failure at the anchorage zone were used to determine the static tensile strength of the CFRP tendons which served as a reference in the later creep tests. The static elastic modulus was calculated from the data points from 20 and $50 \%$ of the ultimate tensile strength.

\subsubsection{Creep Test Loading Procedure}

The long-term behavior of CFRP tendons has been proved to be influenced by external conditions, such as alkaline and acidic environments and temperature [12]. Limited by experimental conditions, in this work, the creep tests were carried out only at room temperature in air. Three groups of creep tests were conducted, and each group consisted of three specimens. The specimen ID and corresponding stress levels are listed in Table 1 . The mass blocks were added block by block slowly so as to ensure that the increase rate of the stress in the tendon was approximately $200 \mathrm{MPa} / \mathrm{min}$ [21]. Once the prescribed stress value was attained, the data were recorded at the following times: 1, 3, 6, 9, 15, 30, $45 \mathrm{~min}$ and $1,1.5,2,4,10,24,48,72,96,120 \mathrm{~h}$. Subsequent measurements were taken once every $120 \mathrm{~h}$. After $1000 \mathrm{~h}$ of the creep test, the specimens were taken down for tensile strength tests to measure the residual strength and elastic modulus.

Table 1. Load levels for the creep tests.

\begin{tabular}{cc}
\hline Creep Specimen ID & Creep Stress Level \\
\hline CC1-i $(\mathrm{i}=1 \sim 3)$ & $0.69 f_{u}$ \\
CC2-i $(\mathrm{i}=1 \sim 3)$ & $0.76 f_{u}$ \\
CC3-i $(\mathrm{i}=1 \sim 3)$ & $0.85 f_{u}$ \\
\hline
\end{tabular}

Note: In column 1 (creep specimen ID), the first letter " $\mathrm{C}$ " represents carbon fiber reinforced polymer (CFRP) and the second letter " $\mathrm{C}$ " represents creep tests. " $f_{u}$ " represents the ultimate tensile strength of the CFRP tendons.

\section{Results and Discussion}

\subsection{Static Tensile Properties}

All the specimens for static tensile tests failed in a similar mode, as shown in Figure 5. Instantaneous fracture at the middle region took place and was accompanied by a loud sound, and the complete dispersal of CFRP fibers could be observed. No premature failure or slippage at the anchorage zone was observed, which verified the efficiency of this anchorage system. The static tensile test results are listed in Table 2. The mean values of the tensile strength and elastic modulus are $2159 \mathrm{MPa}$, with a variation coefficient of $4.1 \%$, and $147.3 \mathrm{GPa}$, with a variation coefficient of $0.95 \%$. The small variation coefficients demonstrate the stability of the CFRP tendons. For design considerations, a 95\% guaranteed strength of $2012 \mathrm{MPa}$ is derived from Equation (1) [22].

$$
f_{u k}=\overline{f_{u}}-1.645 \sigma_{f}
$$

where $f_{u k}, \overline{f_{u}}$ and $\sigma_{f}$ are the $95 \%$ guaranteed strength, mean value, and standard deviation of the ultimate strength, respectively.

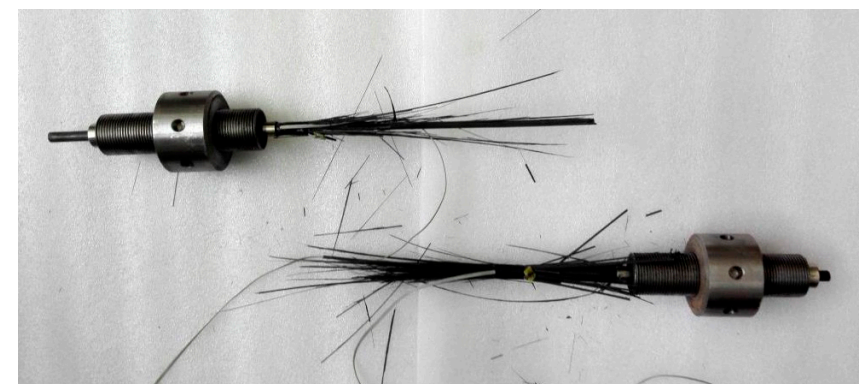

Figure 5. Failure mode of CFRP tendons. 
Table 2. Static test results.

\begin{tabular}{ccccc}
\hline & $\begin{array}{c}\text { Tensile } \\
\text { Capacity/kN }\end{array}$ & $\begin{array}{c}\text { Tensile } \\
\text { Strength/MPa }\end{array}$ & $\begin{array}{c}\text { Elastic } \\
\text { Modulus/GPa }\end{array}$ & Rupture Strain/\% \\
\hline Mean value & 108.6 & 2159 & 147.3 & 1.47 \\
Standard deviation & 4.51 & 89.57 & 1.39 & 0.054 \\
Variation coefficient & 0.041 & 0.041 & 0.0095 & 0.037 \\
\hline
\end{tabular}

Note: In column 1 (specimen ID), the first letter " $\mathrm{C}$ " represents $C F R P$ and the second letter " $\mathrm{S}$ " represents static tests.

\subsection{Creep Properties}

\subsubsection{Creep Curve}

The strain of each specimen recorded over time is plotted in Figure 6. A continuous increase in strain is characterized for all specimens. Since no creep rupture phenomenon was observed in any of the creep tests, the $\varepsilon-T$ relationships are characterized by two stages instead of the typical three stages [11]. At the first stage, the strain increases at a relatively rapid speed. Then, the rates of creep slow down gradually and go into the second stage, which is stable and lasts for a long time. This development law is in accordance with the results observed in creep tests of other composite materials [23]. Furthermore, the specimens under higher creep stress levels are characterized by larger creep strains. This is because higher stress leads to straighter fibers and larger viscous deformation of the resin matrix. Several fluctuations can be observed in the creep curves, which are caused by the measurement error and thermal deformation of the testing device.
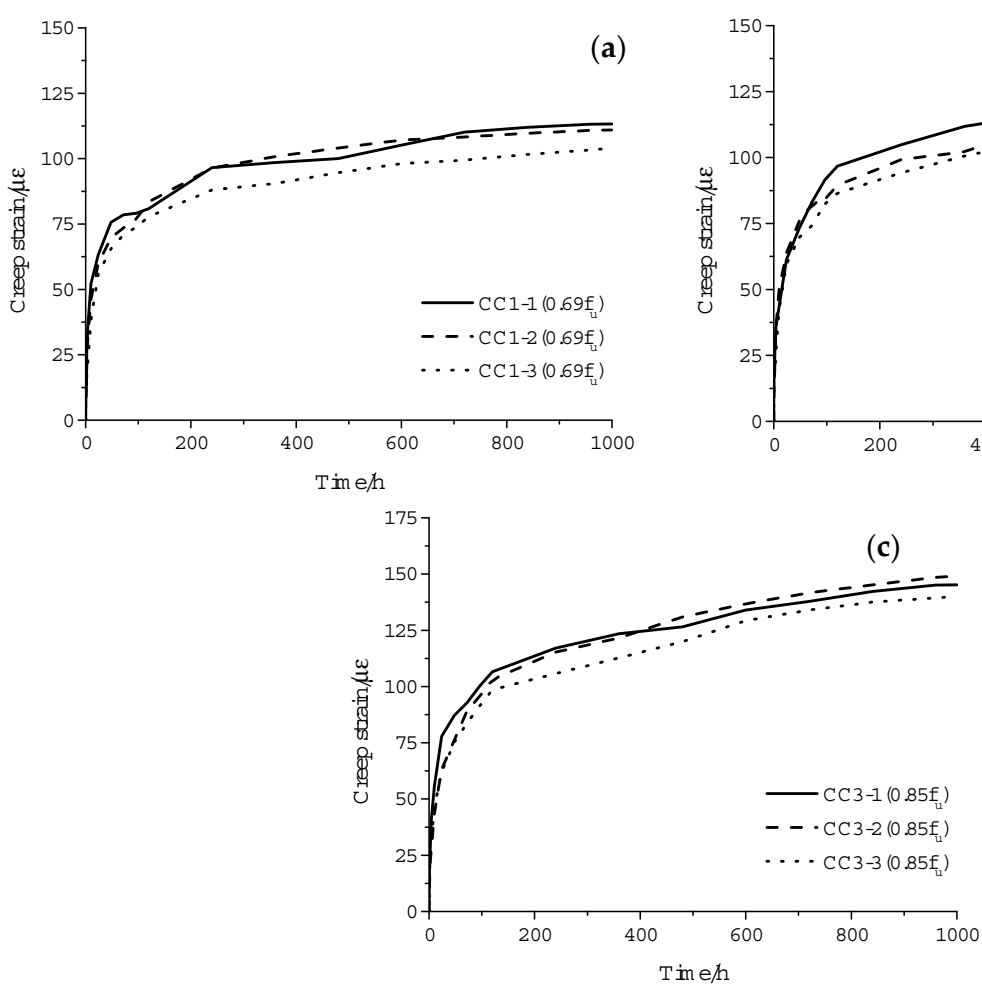

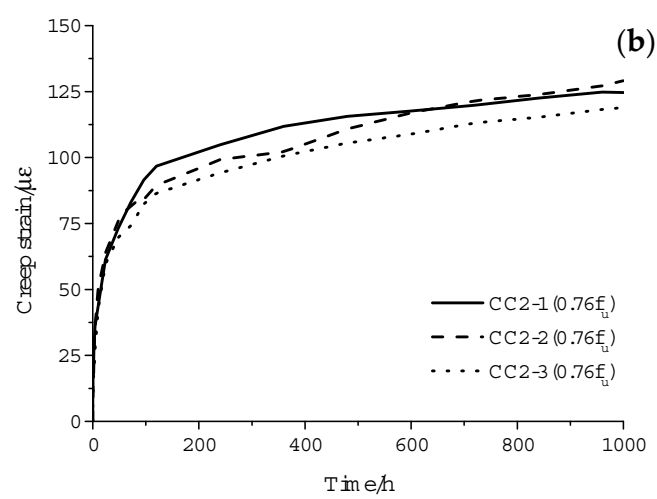

(b)

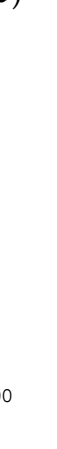


levels [23]. A defect expansion mechanism was developed and gives a reasonable explanation for this phenomenon. With the increase in stress, the development of the original defects in the FRP material becomes more sufficient, and this appears as better uniformity of the specimens [23]. The test results in this paper can also be explained by this theory.

Table 3. Creep coefficient (CC) of CFRP specimens.

\begin{tabular}{cccccccccc}
\hline \multirow{2}{*}{ Specimen ID } & \multicolumn{3}{c}{ CC1 $\left(\mathbf{0 . 6 9} f_{u}\right)$} & \multicolumn{3}{c}{ CC2 $\left(\mathbf{0 . 7 6} f_{u}\right)$} & \multicolumn{3}{c}{ CC3 (0.85 $\left.f_{u}\right)$} \\
\cline { 2 - 11 } & $\mathbf{1}$ & $\mathbf{2}$ & $\mathbf{3}$ & $\mathbf{1}$ & $\mathbf{2}$ & $\mathbf{3}$ & $\mathbf{1}$ & $\mathbf{2}$ & $\mathbf{3}$ \\
\hline Creep coefficient $(1000 \mathrm{~h}, \%)$ & 1.12 & 1.10 & 1.03 & 1.11 & 1.15 & 1.06 & 1.19 & 1.16 & 1.13 \\
\hline Mean value $(\%)$ & & 1.08 & & & 1.11 & & & 1.16 \\
Standard deviation $(\%)$ & & 0.047 & & & 0.045 & & 0.030 \\
Variation coefficient & & 0.0436 & & & 0.0407 & & \multicolumn{2}{c}{0.0259} \\
\hline
\end{tabular}

\subsubsection{Residual Tensile Strength and after-Creep Elastic Modulus}

To assess the influence of sustained stress on the mechanical properties of CFRP tendons, all the creep specimens were reloaded to failure after the creep tests. The failure modes are the same as those in static tensile tests. No premature failure at the anchorage zone was observed, which illustrates that the performance of the anchorage did not degrade under a sustained load. From the test results listed in Table 4, we can see that compared with the static tensile test results, the average residual tensile strength (2061 MPa) decreases by $4.54 \%$, while the average after-creep elastic modulus (157.6 GPa) increases by $6.99 \%$ and the rupture strain $(1.28 \%)$ decreases by $12.9 \%$. Moreover, no significant trend can be found for the residual properties of the specimens treated at different stress levels. This phenomenon can be explained as follows. Sustained high stress is likely to cause damage to the interface between the fibers and resin, and the damage would expand rapidly under high stress near failure and weaken the collaboration between the fiber and resin matrix, leading to a decrease in residual strength [24]. Meanwhile, the original uneven fibers were straightened during the creep tests; thus, the collaboration of the fibers improves and the after-creep elastic modulus increases. As for the specimens CC1-CC3, based on previous creep rupture research on CFRP tendons [10,11], no creep rupture is likely to take place in a short period of time under the designed creep stress levels. This means that the damage evolution inside the material in previous creep tests was stable, and the deterioration of all the specimens was restrained to a certain degree, resulting in a slight discrepancy in the residual properties.

Table 4. Residual tensile strength and after-creep elastic modulus.

\begin{tabular}{ccccc}
\hline & $\begin{array}{c}\text { Tensile } \\
\text { Capacity/kN }\end{array}$ & $\begin{array}{c}\text { Tensile } \\
\text { Strength/MPa }\end{array}$ & $\begin{array}{c}\text { Elastic } \\
\text { Modulus/GPa }\end{array}$ & Rupture Strain/\% \\
\hline Mean value & 103.7 & 2061 & 157.6 & 1.28 \\
Standard deviation & 4 & 79.5 & 1.88 & 0.047 \\
Variation coefficient & 0.039 & 0.039 & 0.012 & 0.037 \\
\hline
\end{tabular}

\subsubsection{Creep Coefficient Prediction}

Although various models have been developed for the creep behavior of plastic materials [25], a universally applicable model for the prediction of creep behavior in FRP materials is still lacking. Equations (2)-(6) are several classical creep relations [13,25] and are compared to the creep test results. Due to limited space, only the comparison results for specimens CC1-1 and CC3-3 are plotted in Figure 7.

$$
\begin{gathered}
\varepsilon_{c}=\varepsilon-\varepsilon_{0}=a \ln t+b \\
\varepsilon_{\mathcal{c}}=\varepsilon-\varepsilon_{0}=a \ln t+b t \\
\varepsilon_{c}=\varepsilon-\varepsilon_{0}=a t^{b}
\end{gathered}
$$




$$
\begin{gathered}
\varepsilon_{c}=\varepsilon-\varepsilon_{0}=a\left(1-e^{-b t}\right) \\
\varepsilon_{c}=\varepsilon-\varepsilon_{0}=a\left(1-e^{-b t}\right)+c t
\end{gathered}
$$

where $t$ is the time in hours, $\varepsilon_{c}$ and $\varepsilon$ are the creep strain and total strain at time $t$, respectively, $\varepsilon_{0}$ is the initial elastic strain, and $a, b$, and $c$ are empirical constants.
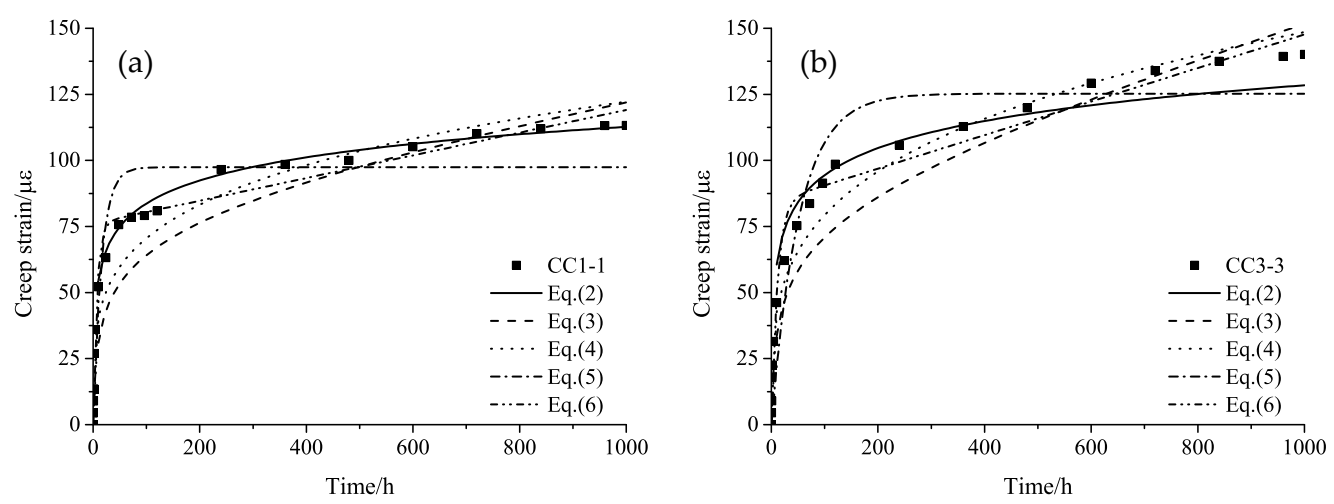

Figure 7. The fitting curves of different models for specimens (a) CC1-1 and (b) CC3-3.

It can be seen from Figure 7a that the fitting curves of Equation (2) are very close to the test data. The fitting curves of Equations (3) and (4) are similar and underestimate the creep strain at the earlier stage, while they overestimate it latterly. A rapid increase in creep strain is observed at the beginning of the curve of Equation (5), and the strain becomes stable after $100 \mathrm{~h}$, which does not match the test data. The curve of Equation (6) fits well with the test data at the first stage, but it becomes almost linear afterward. The calculated strain will be far larger than the actual value at the later stage.

The fitting result in Figure $7 \mathrm{~b}$ is similar to that in Figure 7a, in general. However, the curve of Equation (2) obviously underestimates the strain at the later stage.

The fitting results for specimens CC1-2, CC1-3, CC2-1, CC2-2, CC2-3, and CC3-1 are similar to that for CC1-1, and the result for specimen CC3-2 is similar to that of CC3-3. From a comparison, we can see that for specimens CC3-2 and CC3-3, the increase rate of the creep strain at the second stage are obviously higher than those of other specimens. From the creep rupture test results in previous research in References [10,11], we can speculate that the stress level of $0.85 f_{u}$ may have been close to or already exceeding the creep rupture stress of the CFRP tendons. Under such a sustained high stress level, parts of the fibers start to fracture gradually, resulting in the stress and strain increase in the maintained fibers. Given a longer test duration, creep rupture might take place in these tests.

Based on the above analysis, Equation (2) fits the creep strain test data with the best precision. This calculation model considers the creep coefficient of CFRP tendons to be linear with the logarithm of time, which is reasonable and agrees with the research conclusion drawn by Patrick X. W. Zou [13] from the creep study of AFRP tendons. It can be rewritten as Equation (7) for the long-term creep coefficient prediction of CFRP tendons.

$$
\varphi(t)=\varepsilon_{c} / \varepsilon_{0}=a \ln t / \varepsilon_{0}+b / \varepsilon_{0}
$$

Constants $a$ and $b$ for a certain load level can be determined by regression analysis of the corresponding data obtained during the $1000 \mathrm{~h}$ creep test. Then, the creep coefficients of the CFRP after $1000 \mathrm{~h}$ can be predicted by substituting $a$ and $b$ into Equation (7). The prediction results are listed in Table 5.

As can be seen from Table 5, the difference between the predicted creep coefficients of the CFRP tendons at 50 years and 1 million hours under sustained stresses from $0.69 f_{u}$ to $0.85 f_{u}$ is small. Basically, this phenomenon stays the same as that observed in the results of the $1000 \mathrm{~h}$ test. According to the analysis in Figure 7, it can be speculated that the predicted creep values for stress levels of $0.69 f_{u}$ and 
$0.76 f_{u}$ are reliable, while a considerable underestimation can be foreseen for the creep prediction for stress level of $0.85 f_{u}$. Still, more tests with longer duration times are necessary for the verification of this conclusion.

Table 5. Constant values and predicted creep coefficient.

\begin{tabular}{|c|c|c|c|c|c|c|c|c|}
\hline \multirow{2}{*}{\multicolumn{2}{|c|}{ Specimen ID }} & \multicolumn{2}{|c|}{ Constants } & \multirow{2}{*}{ Regression Coefficient } & \multicolumn{4}{|c|}{ Creep Coefficient (\%) } \\
\hline & & $a$ & $b$ & & 50 Year & Mean Value & $10^{6} \mathrm{~h}$ & Mean Value \\
\hline \multirow{3}{*}{ CC1 $\left(0.69 f_{u}\right)$} & 1 & 12.14 & 25.50 & 0.966 & 1.81 & \multirow{3}{*}{1.75} & 1.91 & \multirow{3}{*}{1.84} \\
\hline & 2 & 12.07 & 24.67 & 0.965 & 1.79 & & 1.89 & \\
\hline & 3 & 11.09 & 22.94 & 0.959 & 1.65 & & 1.74 & \\
\hline \multirow{3}{*}{ CC2 $\left(0.76 f_{u}\right)$} & 1 & 13.04 & 29.70 & 0.967 & 1.77 & \multirow{3}{*}{1.74} & 1.87 & \multirow{3}{*}{1.83} \\
\hline & 2 & 12.99 & 28.56 & 0.962 & 1.76 & & 1.85 & \\
\hline & 3 & 12.46 & 24.94 & 0.958 & 1.66 & & 1.76 & \\
\hline \multirow{3}{*}{ CC3 $\left(0.85 f_{u}\right)$} & 1 & 15.32 & 31.11 & 0.964 & 1.84 & \multirow{3}{*}{1.81} & 1.94 & \multirow{3}{*}{1.91} \\
\hline & 2 & 15.85 & 26.54 & 0.943 & 1.86 & & 1.96 & \\
\hline & 3 & 14.76 & 26.44 & 0.952 & 1.74 & & 1.84 & \\
\hline
\end{tabular}

\section{Conclusions}

In this study, an experimental study was carried out on the creep property of CFRP tendons with a wedge-type anchorage that was developed by the authors' research group. The main conclusions are as follows.

(1) The creep curves for all the specimens under sustained stresses from $0.69 f_{u}$ to $0.85 f_{u}$ are similar and can be divided into two stages. The creep strain increases quickly in the first stage and becomes stable in the second stage. Generally, a higher creep stress leads to a larger creep coefficient. The creep coefficients at $1000 \mathrm{~h}$ vary from 1.08 to $1.16 \%$.

(2) Compared to their static properties, the CFRP tendons' residual strength after creep tests of $1000 \mathrm{~h}$ is $4.54 \%$ lower, while the after-creep elastic modulus is $6.99 \%$ higher.

(3) A semi-logarithm relationship is found to fit the creep data within $1000 \mathrm{~h}$ with an acceptable precision. Through the extrapolation of this relationship, the creep coefficients at 1 million hours under stress levels of $0.69-0.85 f_{u}$ are $1.83-1.91 \%$. However, under stress levels close to or exceeding the creep rupture stress of CFRP tendons, the creep coefficients predicted by this relationship are smaller than the actual values.

(4) No premature failure at the anchorage zone was observed in any of the tests. The $8 \mathrm{~mm}$ wedge-type anchorage developed by the authors' research group performed well in both the static and creep tests.

Supplementary Materials: The following are available online at http:/ /www.mdpi.com/1996-1944/11/11/2273/ s1.

Author Contributions: Conceptualization, J.Z. and D.Y.; methodology, D.Y. and S.S.; software, D.Y.; validation, F.Z. and C.W.; formal analysis, D.Y.; investigation, D.Y., F.Z. and C.W.; resources, D.Y., F.Z. and C.W.; data curation, D.Y.; writing — original draft preparation, D.Y.; writing—review and editing, J.Z. and S.S.; visualization, D.Y.; supervision, J.Z.; project administration, J.Z.; funding acquisition, J.Z. and S.S.

Funding: This research was funded by National Key Research and Development Program of China (No. 2017YFC0703006-01) and Jiangsu Postdoctoral Research Foundation (No. 1601148B).

Acknowledgments: The authors acknowledge Jiangsu Hengshen Co. Ltd. (Zhenjiang, China) for providing CFRP tendons and Jiangsu Yiding electric power technology Co. Ltd. (Suqian, China) for providing anchorages.

Conflicts of Interest: The authors declare no conflict of interest.

\section{References}

1. El-Hacha, R. Prestressing Concrete Structures with FRP Tendons (ACI 440.4R-04). In Proceedings of the Structures Congress 2005: Metropolis and Beyond, New York, NY, USA, 20-24 April 2005; pp. 1-8. 
2. MacDougall, C.; Green, M.; Amato, L. CFRP Tendons for the Repair of Posttensioned, Unbonded Concrete Buildings. J. Perform. Constr. Facil. 2010, 25, 149-157. [CrossRef]

3. Ge, W.; Zhang, J.; Cao, D.; Tu, Y. Flexural behaviors of hybrid concrete beams reinforced with BFRP bars and steel bars. Constr. Build. Mater. 2015, 87, 28-37. [CrossRef]

4. Wang, X.; Wu, Z. Evaluation of FRP and hybrid FRP cables for super long-span cable-stayed bridges. Compos. Struct. 2010, 92, 2582-2590. [CrossRef]

5. Braimah, A.; Green, M.F.; SOUDKI, K.A. Long-term behavior of CFRP prestressed concrete beams. PCI J. 2003, 48, 98-107. [CrossRef]

6. Ascione, L.; Berardi, V.P.; D'Aponte, A. Creep phenomena in FRP materials. Mech. Res. Commun. 2012, 43, 15-21. [CrossRef]

7. Oskouei, A.V.; Taleie, S.M. Experimental Investigation of Relaxation of Fiber-reinforced Polymer Composites. J. Reinf. Plast. Compos. 2010, 29, 2705-2718. [CrossRef]

8. Andrä, H.-P.; Maier, M. Carbon fibre composites for a new generation of tendons. The Application of Codes, Design and Regulations. In Proceedings of the International Conference, Scotland, UK, 5-7 July 2005.

9. Zang, H.; Liu, Z.; Lv, Z.-T.; Mei, K.-H. Research and Application Review on CFRP Cables for Cable-stayed Bridges. J. Highw. Transp. Res. Dev. 2007, 2, 29-33. [CrossRef]

10. Yamaguchi, T.; Nishimura, T.; Uomoto, T. Creep rupture of FRP rods made of aramid, carbon and glass fibers. Struct. Eng. Constr. Tradit. Present Future 1998, 2, 1331-1336.

11. Ando, N.; Matsukawa, H.; Kawamura, M.; Fujii, M.; Miyagawa, T.; Inoue, S. Experimental studies on the long-term tensile properties of FRP tendons. In Proceedings of the FRAMCOS-3 D-79104, Freiburg, Germany, 20-22 January 1998.

12. Saadatmanesh, F.E. Relaxation, creep, and fatigue behavior of carbon fiber reinforced plastic tendons. ACI Mater. J. 1999, 96, 143-153.

13. Zou, P.X.W. Long-term properties and transfer length of fiber-reinforced polymers. J. Compos. Constr. 2003, 7, 10-19. [CrossRef]

14. Yang, X.; Arockiasamy, M.; Mirmiran, A.; Potter, W. High Creep Stress Test of Carbon Fiber-Composite Cable with Generic Field-Made Anchorage. J. Compos. Constr. 2017, 21, 06017001. [CrossRef]

15. Schmidt, J.W.; Bennitz, A.; Täljsten, B.; Goltermann, P.; Pedersen, H. Mechanical anchorage of FRP tendons-A literature review. Constr. Build. Mater. 2012, 32, 110-121. [CrossRef]

16. Wang, L.; Zhang, J.; Xu, J.; Han, Q. Anchorage systems of CFRP cables in cable structures-A review. Constr. Build. Mater. 2018, 160, 82-99. [CrossRef]

17. Geffroy, R.-L. The Laroin footbridge with carbon composite stay-cables. In Proceedings of the Footbridge, Paris, France, 20-22 November 2002.

18. Nanni, A.; Bakis, C.E.; O'Neil, E.F.; Dixon, T.O. Short-term sustained loading of FRP tendon anchor systems. Constr. Build. Mater. 1996, 10, 255-266. [CrossRef]

19. Al-Mayah, A.; Soudki, K.; Plumtree, A. Development and assessment of a new CFRP rod-anchor system for prestressed concrete. Appl. Compos. Mater. 2006, 13, 321-334. [CrossRef]

20. Xiaoya, Z. Experimental Study on the Fatigue Behavior of Prestressing CFRP Tendon-Anchorage Assembly. Master's Thesis, Southeast University, Nanjing, China, 2015.

21. Japan Society of Civil Engineers. Test Method for Tensile Properties of Continuous Fiber Reinforcing Materials; Japan Society of Civil Engineers: Tokyo, Japan, 1995.

22. China Architecture \& Building. Technical Code for Infrastructure Application of FRP Composites; China Architecture \& Building Press: Beijing, China, 2010. (In Chinese)

23. Wang, X.; Shi, J.; Liu, J.; Yang, L.; Wu, Z. Creep behavior of basalt fiber reinforced polymer tendons for prestressing application. Mater. Des. 2014, 59, 558-564. [CrossRef]

24. Shi, J.; Wang, X.; Wu, Z.; Zhu, Z. Creep behavior enhancement of a basalt fiber-reinforced polymer tendon. Constr. Build. Mater. 2015, 94, 750-757. [CrossRef]

25. Findley, W. Mechanism and mechanics of creep of plastics. SPE J. 1960, 16, 57-65.

(C) 2018 by the authors. Licensee MDPI, Basel, Switzerland. This article is an open access article distributed under the terms and conditions of the Creative Commons Attribution (CC BY) license (http://creativecommons.org/licenses/by/4.0/). 